\title{
Multi-Objective Optimization Phase-Shift Control Strategy for Dual-Active-Bridge Isolated Bidirectional DC-DC Converter
}

\author{
Xiaodong X $u^{1}$, Guangqing Bao ${ }^{1}$, Ming Ma', Yuewu Wang ${ }^{3}$ \\ ${ }^{1}$ College of Electrical and Information Engineering, Lanzhou University of Technology, Lanzhou, China \\ ${ }^{2}$ Wind Power Technology Center, State Grid Gansu Electric Power Corporation, Lanzhou, China \\ ${ }^{3}$ School of Electrical Engineering and Automation, Harbin Institute of Technology, Harbin, China
}

\begin{abstract}
The dual-active-bridge isolated bidirectional DC-DC converter (DAB-IBDC) is a crucial device for galvanic isolation, voltage conversion, power transfer, and bus connection in the DC power conversion systems. Phase-shift modulation is an effective method to improve DAB-IBDC performance. However, the phase-shift control strategies in the previous literatures mainly focus on optimizing the characteristic of DAB-IBDC in a single aspect. In this paper, to optimize high-frequency-link (HFL) reactive power, current stress, and efficiency simultaneously, a new multi-objective optimization strategy based on dual-phase-shift (DPS) control is proposed. The power characterization, current stress, and power loss of the DAB-IBDC are analyzed. Besides, both the control principle and framework of the proposed control strategy are described in detail. Finally, the experiment results obtained from an established DAB-IBDC prototype are presented to verify the correctness and superiority of the proposed strategy.
\end{abstract}

Keywords: dual-active-bridge; multi-objective optimization; DPS control strategy; electrical performance

\section{Strategija upravljanja faznega premika z več ciljnimi optimizacijami za dvoaktivni izolirani mostič dvosmernega DC-DC pretvornika}

\begin{abstract}
Izvleček: Izolirani dvosmerni DC-DC (DAB-IBDC) pretvornik z dvoaktivnim mostičem je ključna naprava za galvansko izolacijo, pretvorbo napetosti, prenos moči in povezavo vodila v sistemih za pretvorbo enosmerne energije. Modulacija s faznim zamikom je učinkovita metoda za izboljšanje delovanja DAB-IBDC. Vendar se strategije nadzora s faznim zamikom v dosedanji literaturi osredotočajo predvsem na optimizacijo značilnosti DAB-IBDC z enega vidika. V tem članku je za hkratno optimizacijo jalove moči, tokovne napetosti in učinkovitosti visokofrekvenčne povezave (HFL) predlagana nova večpredmetna strategija optimizacije, ki temelji na nadzoru z dvojnim faznim zamikom (DPS). Analizirane so značilnosti moči, tokovne obremenitve in izgube moči DAB-IBDC. Poleg tega sta podrobno opisana tako načelo krmiljenja kot tudi okvir predlagane strategije krmiljenja. Na koncu so predstavljeni rezultati poskusov, pridobljeni iz vzpostavljenega prototipa DAB-IBDC, s katerimi sta preverjeni pravilnost in superiornost predlagane strategije.
\end{abstract}

Ključne besede: dvojni aktivni mostič; večnamenska optimizacija; strategija krmiljenja DPS; električna zmogljivost

*Corresponding Author's e-mail:gqbao@/ut.cn

\section{Introduction}

With the wide application of direct-current (DC) renewable power sources, DC loads, and storage equipment, DC power conversion systems (PCS) have considerable potential for engineering applications [1-4]. With the development of power electronics, isolated bidirectional DC-DC converters (IBDCs) have become popular for galvanic isolation, voltage conversion, and power transfer in DC PCS [5-6]. Among various IBDCs, the du- 
al-active-bridge (DAB) IBDC with merits of symmetric topology and control structure, the convenience of implement zero voltage switching for switches, bidirectional power transmission, and cascaded modularity, has been studied and applied in the DC PCS. Thanks to the development of novel power devices and technologies, the DAB-IBDC performance is greatly improved under the great efforts of researchers and engineers. The improvements in DAB-IBDC also promote the development of PCS, so bringing lots of technical advantages [7-10].

The improvements of DAB-IBDC in the previous literatures mainly focus on the topology design and optimization, mathematical model derivation, phase-shift modulation strategies, converter control schemes, and soft-switching realization [11-15]. Particularly, the phase-shift control is an effective method to optimize the DAB-IBDC performance [16]. The phase-shift control strategies can be categorized into single-phaseshift (SPS), extended-phase-shift (EPS), dual-phaseshift (DPS), and triple-phase-shift (TPS). With DAB configurations each full bridge is driven with specific phase-shift. While these phase-shifts can differ in DPS they are equal and referred as inner phase-shift, and phase-shift between each full bridge is the outer phaseshift [7]. The SPS has one degree of freedom with outer phase-shift, and the EPS and DPS have two degrees of freedom with inner phase-shift and outer phase-shift, while the TPS has three degrees of freedom with two different inner phase-shifts and an outer phase-shift. In [17], an improved asymmetric modulation for both-side of DAB-IBDC is proposed, enabling the smooth transaction during steady-state operation and minimizing the transient time regardless of equivalent resistance of inductor. In [18], optimized phase-shift modulations are proposed to accelerate the transient response and suppress the DC bias during transient process. In [19-20], a mathematical model of current stress for DAB-IBDC is established, and the minimum current stresses are achieved under DPS and TPS control strategies, respectively. In [21-22], the DAB-IBDCs with soft-switching operation during whole operating range are analyzed, expanding the zero-voltage switching (ZVS) range and promoting efficiency. In [23-24], the power loss and efficiency models are established, and the efficiency optimized modulation schemes based on phase-shift control are developed. Other phase-shift modulation strategies are also proposed in [25-28] to eliminate reactive power, reduce the peak and root-mean-square (RMS) values of HFL current, and enhance light-load performance for DAB-IBDC, respectively. Moreover, the phase-shift strategies with quasi-square-wave, triangle-wave and sine-wave modulation are investigated for improving performance under varied modulation methods [29-30]. Besides, the TPS control strategy is an efficient method to improve the performance of $D A B$ [31-33].

The phase-shift control strategies in the previous literatures have improved the performance of DAB-IBDC effectively. However, most existing phase-shift control strategies only realize the performance optimization in a single aspect (e.g., current stress, reactive power elimination, ZVS behavior, or efficiency performance of DAB-IBDC). The phase-shift control strategy for multiobjective optimization, i.e., simultaneously optimizes various characteristics of DAB-IBDC, has not been considered and discussed yet. Besides, some phaseshift control strategies with optimal phase-shift angle contain lots of electrical parameters, nonlinear equations, or trigonometric calculation, leading to a high computational burden, a complicated process, and a poor real-time characteristic in practical application. In this paper, to address the above problems and achieve the comprehensive optimization for DAB-IBDC, a multiobjective optimization strategy with DPS control is proposed. The proposed strategy can reduce current stress, improve transmission power, and minimize power loss simultaneously. Consequently, the proposed strategy can achieve high efficiency and improve adaptability and practicality for DAB-IBDC, which promotes the application of DAB-IBDC and also accelerates the development of DC PCS.

This paper is organized as follows. The topology, switching behavior based on DPS control, and the performance characteristics including the high-frequencylink (HFL) current stress, power factor, and power loss of the DAB-IBDC are investigated in Section 2. On this basis, a multi-objective optimization based on DPS control is proposed in Section 3. Then, Section 4 provides the experimental results obtained from a built DAB-IBDC prototype to verify the proposed strategy.

\section{Performance characteristics of $D A B$ - IBDC under DPS control}

The topology of the DAB-IBDC is presented in Fig. 1. The DAB-IBDC is consisted of active full-bridges $\mathrm{H}_{1}$ and $\mathrm{H}_{2}$, two DC capacitors $C_{1}$ and $C_{2}$, an auxiliary inductor $L_{T}$ and an high-frequency-link (HFL) transformer with a conversion ratio $n . S_{1} \sim S_{4}$ and $D_{1} \sim D_{4}$ are switches and diodes in $\mathrm{H}_{1}$, respectively, and $\mathrm{Q}_{1} \sim \mathrm{Q}_{4}$ and $\mathrm{M}_{1} \sim \mathrm{M}_{4}$ are switches and diodes in $\mathrm{H}_{2}$, respectively. $V_{1}$ and $V_{2}$ are $D C$ voltages on two sides of DAB-IBDC, respectively. The energy transfer could be equivalent to the transmission of energy between two modulated voltage sources through equivalent inductor $L . i_{L}$ is HFL current flowing through the equivalent inductor. $v_{\mathrm{p}}$ is the HFL 
voltage on the primary side. $v_{\mathrm{s}}$ is the HFL voltage on the secondary side, which is generated by secondary terminate and equivalent to the primary-side voltage.

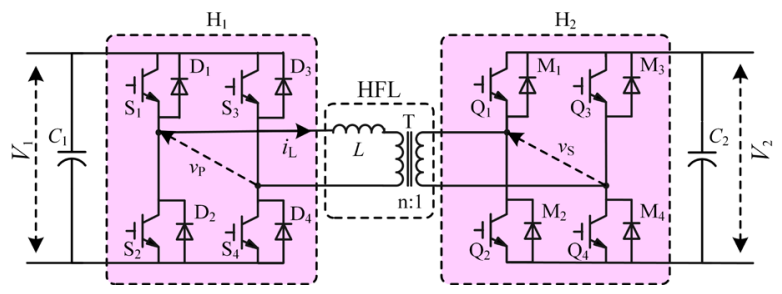

Figure 1: Topology configuration of DAB-IBDC.

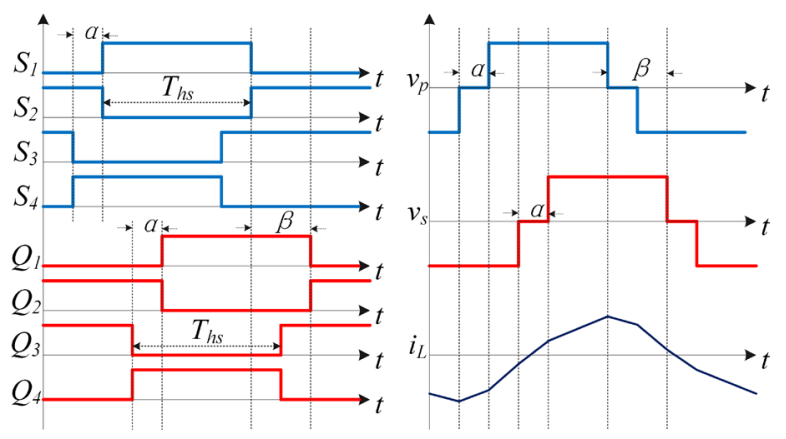

Figure 2: The operation principle, HFL voltages, and currents under DPS control.

Generally, the DPS control has two working modes: the inner phase-shift ratio is larger or smaller than the outer phase-shift ratio, which is determined by the transferred power [7]. Different from EPS and TPS, the inner phase-shift ratios under DPS strategy in active fullbridges on both sides are the same. $T_{s}$ is the switching period. To avoid the analysis complexity brought from the traditional time-domain segmentation function, the unified model form based on the Fourier series is applied in the analysis and control design. According to the topology of DAB-IBDC, the operation principle, HFL voltages, and currents under DPS control are presented in Fig. 2, where $\beta$ is the outer phase-shift angle between $v_{\mathrm{p}}$ and $v_{\mathrm{s}^{\prime}}$ and $\alpha_{1}=\alpha_{2}=\alpha$ is the inner phaseshift angle.

According to Fourier series, the primary and secondary side HFL voltages $v_{\mathrm{p}}$ and $v_{\mathrm{s}^{\prime}}$ shown in Fig. 2, are:

$$
\left\{\begin{array}{l}
v_{p}(t)=\sum_{k=1,3,5 \ldots} \frac{4 V_{1}}{k \pi} \cos \left(\frac{k \alpha}{2}\right) \sin (n \omega t) \\
v_{s}(t)=\sum_{k=1,3,5 \ldots} \frac{4 V_{2}}{k \pi} \cos \left(\frac{k \alpha}{2}\right) \sin [n(\omega t-\beta)]
\end{array}\right.
$$

Since the average inductor current is equal to zero during steady-state, the HFL current $i_{L}$ in every switching period can be express as:
$i_{L}(t)=\int_{t_{0}}^{t} \frac{v_{P}(t)-v_{S}(t)}{L} d t+i_{L}\left(t_{0}\right)$

From (1) - (2), the following equations can be obtained:

$$
\left\{\begin{array}{l}
i_{L}(t)=\sum_{k=1,3,5 \ldots} \frac{4}{k^{2} \pi \omega L} \sqrt{A^{2}+B^{2}} \sin \left(k \omega t+\arctan \frac{A}{B}\right) \\
A=\cos \left(\frac{k \alpha}{2}\right)\left[V_{2} \cos (k \beta)-V_{1}\right] \\
B=V_{2} \cos \left(\frac{k \alpha}{2}\right) \sin (k \beta)
\end{array}\right.
$$

Thus, the root-mean-square (RMS) value of $i_{L}$ is:

$$
I_{L-R M S}=\sqrt{\sum_{k=1,3,5 \ldots} I_{L k}^{2}}=\sqrt{\sum_{k=1,3,5 \ldots}\left[\frac{2 \sqrt{2}}{k^{2} \pi \omega L} \sqrt{A^{2}+B^{2}}\right]^{2}}
$$

\subsection{Transmission power characterization}

The average transmission power $\mathrm{P}$ can be obtained as:

$$
P=\frac{1}{T_{h s}} \int_{0}^{T_{h s}} v_{p}(t) \bullet i_{L}(t) d t
$$

Substituting (1) - (3) into (5), the average transmission power $\mathrm{P}$ can be further calculated as:

$P=\sum_{k=1,3,5 \ldots} \frac{8 V_{1} V_{2}}{k^{3} \pi^{2} \omega L} \cos ^{2}\left(\frac{k \alpha}{2}\right) \sin (k \beta)$

Besides, the reactive power $\mathrm{Q}$ can be obtained:

$$
\left\{\begin{array}{c}
Q_{k_{1}=k_{2}=k}=\sum_{k=1,3,5 \ldots} \frac{8 V_{1} \cos ^{2}\left(\frac{k \alpha}{2}\right)}{k^{3} \pi^{2} \omega L}\left[V_{1}-V_{2} \cos (k \beta)\right] \\
Q_{k_{1} \neq k_{2}}=U_{a k_{1}} I_{L k_{2}}=\frac{8 V_{1}}{k_{1} k_{2}^{2} \pi^{2} \omega L} \cos \left(\frac{k \alpha}{2}\right) \sqrt{A^{2}+B^{2}}
\end{array}\right.
$$

From (6) - (7), the apparent power $\mathrm{S}$ is calculated as:

$$
S=\sqrt{\sum_{k=1,3,5 \ldots} P_{k}^{2}+\sum_{k=1,3,5 \ldots} Q_{k}^{2}+\sum_{k=1,3,5 \ldots} Q_{k_{1} \neq k_{2}}^{2}}
$$

Finally, the HFL power factor $\lambda$ can be obtained as:

$$
\lambda=P / S
$$

Based on (6) - (9), Fig. 3 shows the HFL power factors under conventional control strategy. In Fig. 3, the HFL power factor $\lambda$ is influenced by phase-shift angles, and the HFL power factors under DPS are higher. Besides, under DPS (DPS $<$ DPS $_{2}<$ DPS $_{3}$ ), with the increasing of inner angle $\alpha$, the HFL power factor $\lambda$ becomes higher correspondingly, decreasing HFL reactive power and increasing efficiency of DAB-IBDC. 


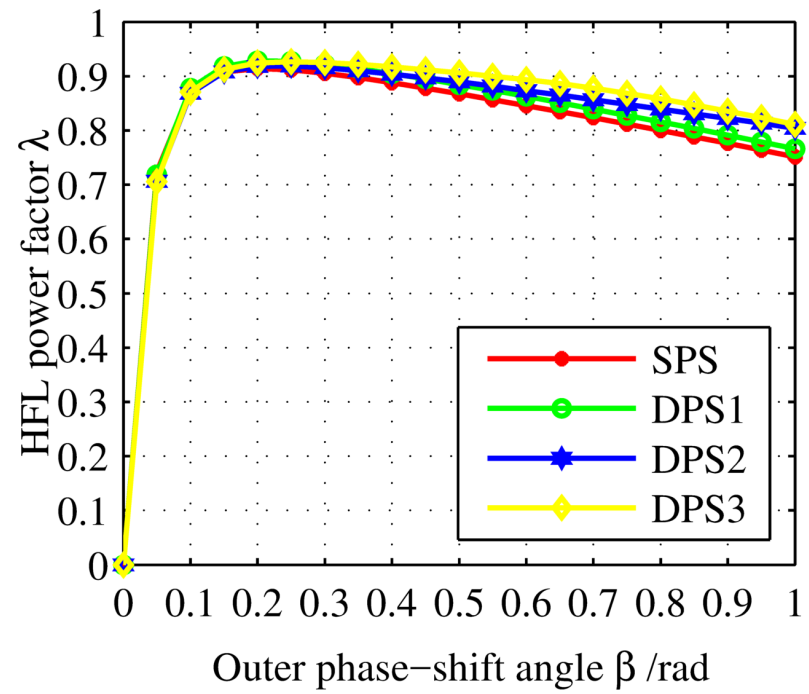

Figure 3: HFL power factors of DAB-IBDC.

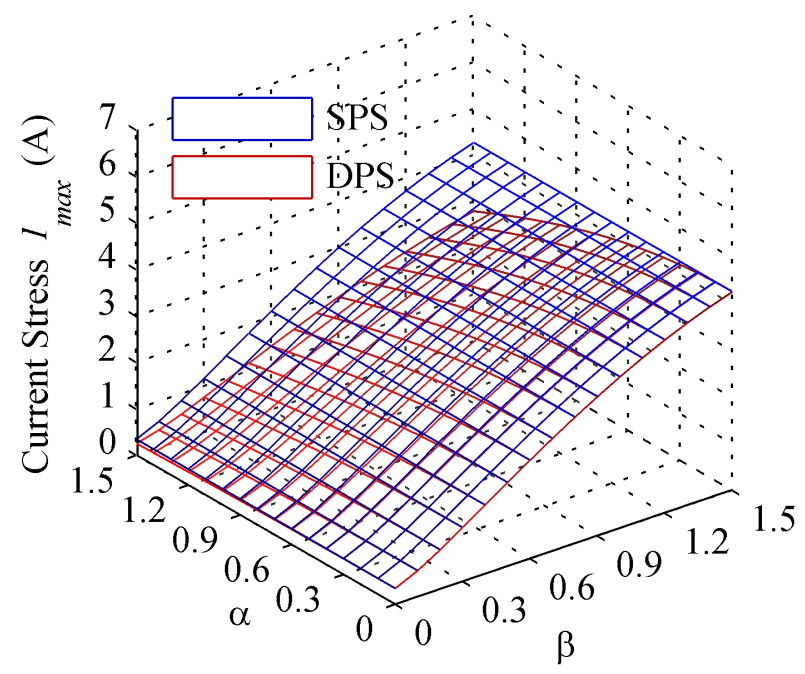

Figure 4: The current stress of DAB-IBDC.

\subsection{Current stress characterization}

To prolong the service life of switching devices, and improve the efficiency of DAB-IBDC, reducing the current stress is an effective solution. In the DAB-IBDC, the maximum value of HFL current $i$, represents the current stress. From (3), it can be observed that the HFL current $i_{\perp}$ compromises components with different frequencies under Fourier series analysis. Since the fundamental component in HFL current $i_{L 1}$ is approximated with HFL current $i_{L}$ during operation, the maximum value of the fundamental component of $i_{L}$ can be considered as the current stress I $_{\max }$ :

$$
I_{\max }=\max \left\{\left|i_{L 1}(t)\right|\right\}=\frac{2 V_{2} \cos \left(\frac{\alpha}{2}\right) \sqrt{1+M^{2}-2 M \cos (\beta)}}{\pi \omega L}
$$

where $M=V_{1} / n V_{2}$ is the voltage conversion ratio of DAB-IBDC.
According to (10), the current stress is closely related to $V_{1}, V_{2^{\prime}} a, \beta$, and M. Fig. 4 presents the current stress $I_{\text {max }}$ with the different $\alpha$ and $\beta$ under the SPS and DPS control. From Fig. 4 , it can be observed: 1 ) with the increase of outer $\beta$, the current stress $I_{\text {max }}$ increases under these two strategies, 2) under the same outer $\beta$, the current stress produced by DPS control is kept smaller. Besides, the current stress can be reduced with the increase of phase-shift a under DPS.

\subsection{Power loss characterization}

For DAB-IBDC, its total power loss $P_{\text {Loss }}$ mainly contains conducting loss $P_{\text {CoN' }}$ switching loss $P_{\text {SW' }}$ and loss of magnetic components $P_{\text {TA }}$ [24].

$$
P_{\mathrm{LOSS}}=P_{\mathrm{CON}}+P_{\mathrm{SW}}+P_{\mathrm{TA}}
$$

(1) Conducting loss: From the topology of DAB-IBDC, the conducting loss $P_{\text {con }}$ is the sum of conducting losses in switches and diodes namely $P_{\text {CONS }}$ and $P_{\text {COND' }}$ respectively. For the DAB-IBDC, the dead-band loss should be considered and could not be ignored. As the zero-voltage-switching (ZVS) for DAB-IBDC can be also realized by using the freewheeling of anti-parallel diodes during dead-band time. Thus, the dead-band current is freewheeling in diodes, which means the deadband loss can be considered as a part of conducting loss. For simplicity, assume that the diodes and switches in DAB-IBDC have the same conducting resistance $R_{\text {CON }}$. Besides, the conducting loss is closely related to the RMS HFL current in primary bridge $\mathrm{H}_{1}$ and secondary bridge $\mathrm{H}_{2}$ namely $I_{1}$ and $I_{2}$, respectively. The relationship between $I_{1}$ and $I_{2}$ is $I_{1}=I_{2} / n=I / \sqrt{2}$. Consequently, the conducting loss of switches and diodes in a switching period are:

$$
P_{\mathrm{CON}}=4 R_{\mathrm{CON}} I_{1}^{2}+4 R_{\mathrm{CON}} I_{2}^{2}=2\left(1+n^{2}\right) R_{\mathrm{CON}} I_{\mathrm{L}-\mathrm{RMS}}^{2}
$$

Based on (12), the conduction losses $P_{\text {CON }}$ is mainly decided by RMS current $I_{\text {L-RMS }}$ of HFL. Under both SPS and DPS control, the conduction loss $P_{\text {CON }}$ for DAB-IBDC are presented in Fig. 5(a), and they are normalized by $P_{\text {CON }}=$ $2\left(1+n^{2}\right) R_{\text {CON }} I_{L-\max }{ }^{2}$. Obviously, with the increase of phaseshift angle $\beta$, the conduction loss $P_{\text {Con }}$ increases, while $P_{\text {CON }}$ under DPS is always smaller. Besides, the conduction loss $P_{\text {CON }}$ drops with the increase of inner phase-shift $\alpha$.

(2) Switching loss: From [24], with the same transfer power, switching loss is relatively smaller compared with the conducting loss and the loss of magnetic components, and it only accounts for a small proportion of the overall power loss of DAB-IBDC. Besides, under soft-switching achievement, the switching loss can be neglected. Thus, for simplicity, the switching loss is ignored here. 
(3) Loss of magnetic components: In DAB-IBDC, magnetic components include the transformer and the auxiliary inductor. Typically, the power loss of magnetic component consists of the copper loss and core loss. Assuming that the winding resistance of magnetic components is constant, the copper loss $P_{\text {copp }}$ is closely related to the RMS value of $i_{L}$. In addition, the RMS value of $i_{\mathrm{L}}$ also plays a major role in the core loss $P_{\text {CORE }}$ The power loss of magnetic components $P_{\mathrm{TA}}$ can be obtained as:

$$
P_{\mathrm{TA}}=P_{\mathrm{COPP}}+P_{\mathrm{CORE}}=\left(R_{\mathrm{tr}}+R_{\mathrm{au}}+\frac{2 m f_{s} \mu_{0}^{2} N^{2} V_{e}}{g^{2}}\right) I_{\mathrm{L}-\mathrm{RMS}}^{2}
$$

where $R_{\mathrm{tr}}$ is the transformer winding resistance while $R_{\mathrm{au}}$ is auxiliary inductor winding resistance. $m$ represents the specific parameter of core loss, $\mu_{0}$ represents the permeability of vacuum, $N$ represents the number of turns, $V_{\mathrm{e}}$ represents the effective core volume, and $g$ represents the air gap of magnetic path.

Based on (13), the power loss $P_{\text {TA }}$ is affected by the RMS current $I_{\text {L-RMS }}$ of HFL. Fig. 5(b) shows the curves of normalized power loss of magnetic components $P_{\mathrm{TA}}$ for DAB-IBDC under DPS, in which they are normalized by

(a)

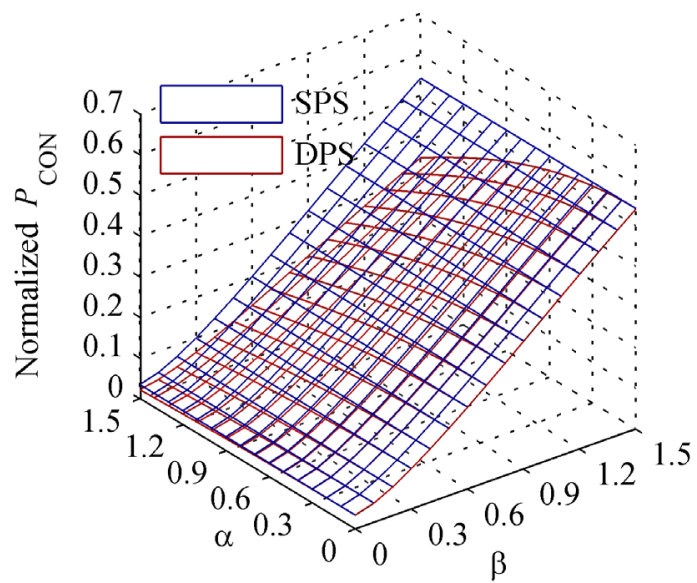

(b)

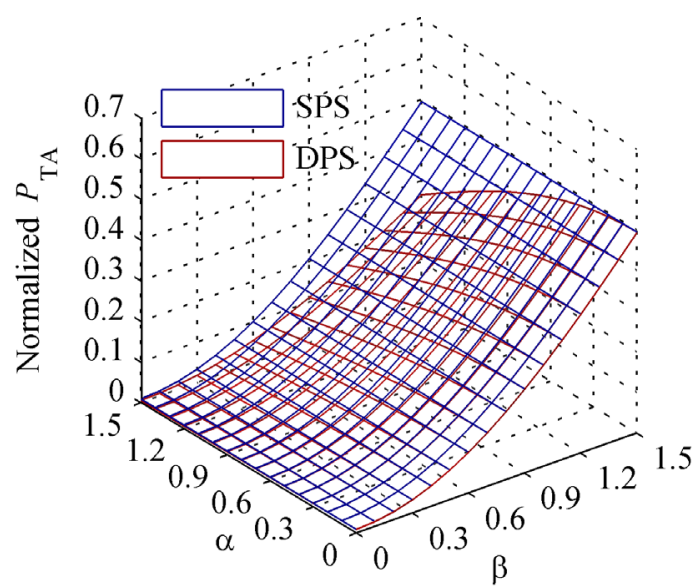

Figure 5: The power loss for DAB-IBDC. (a) Conducting loss, (b) Loss of magnetic components.
$P_{\mathrm{TA}}=\left(R_{\mathrm{tr}}+R_{\mathrm{au}}+2 m f_{\mathrm{s}} u_{0}^{2} N^{2} V_{\mathrm{e}} / g_{2}\right) I_{\mathrm{L}-\mathrm{max}}{ }^{2}$. It is obvious that, the power loss $P_{\text {TA }}$ increases with the raise of outer angle $\beta$, which is smaller under DPS compared with SPS. Besides, the $P_{\text {TA }}$ reduces with the raise of the inner angle $\alpha$.

\section{Multi-objective optimized strategy based on DPS control}

From the analysis above, in the DAB-IBDC, all the HFL reactive power, current stress, and efficiency performance could be optimized by DPS strategy simultaneously. Accordingly, an optimized strategy based on DPS control is investigated for DAB-IBDC.

The current stress $I_{\text {max }}$ conducting loss $P_{\text {con' }}$ and loss of magnetic components $P_{\mathrm{TA}}$ are:

$$
\left\{\begin{array}{l}
I_{\max }=I_{L}=\sqrt{2} I_{\mathrm{L}-\mathrm{RMS}} \\
P_{\mathrm{con}}=2\left(1+n^{2}\right) R_{\mathrm{CON}} I_{\mathrm{L}-\mathrm{RMS}}^{2} \\
P_{\mathrm{TA}}=\left(R_{\mathrm{tr}}+R_{a u}+\frac{2 m f_{s} \mu_{0}^{2} N^{2} V_{e}}{g^{2}}\right) I_{\mathrm{L}-\mathrm{RMS}}^{2}
\end{array}\right.
$$

From (14), it could be seen that the current stress of DABIBDC is affected by the RMS value of HFL current $I_{L-R M S^{*}}$ Besides, the conducting loss $P_{\text {CON }}$ and loss of magnetic components $P_{\mathrm{TA}}$ are also mainly affected by the RMS current of HFL. Thus, through optimizing the HFL current, the current stress, power loss, and the efficiency can be all optimized. Once the optimal RMS value of HFL current is obtained, the optimization of current stress and efficiency for DAB-IBDC could be realized at the same time.

To obtain the optimal RMS value of HFL current, a Lagrangian objective function is constructed:

$E(\alpha, \beta, \lambda)=I_{\mathrm{L}-\mathrm{RMS}}(\alpha, \beta)+\lambda\left(P(\alpha, \beta)-P_{0}\right)$

where $P_{0}$ is the calculated output power for DAB-IBDC, which is obtained through multiplying the reference output voltage $V_{2 \text { ref }}$ by the output current $I_{2}$. Substituting (6) and (10) into (15), the constraints of the optimal equation can be obtained as:

$$
\left\{\begin{array}{c}
E=\frac{2 n V_{2} \cos \left(\frac{\alpha}{2}\right) \sqrt{1+M^{2}-2 M \cos (\beta)}}{\pi \omega L}+ \\
\frac{\left.\partial E \frac{4 V_{1} V_{2} n}{\pi^{2} \omega L} \cos ^{2}\left(\frac{\alpha}{2}\right) \sin (\beta)-P_{0}\right]}{\partial \alpha}=\sqrt{1+M^{2}-2 M \cos (\beta)}+\frac{4 \lambda V_{1}}{\pi} \cos \left(\frac{\alpha}{2}\right) \sin (\beta)=0 \\
\frac{\partial E}{\partial \beta}=\frac{M \sin (\beta)}{\sqrt{1+M^{2}-2 M \cos (\beta)}}+\frac{2 \lambda V_{1}}{\pi} \cos \left(\frac{\alpha}{2}\right) \cos (\beta)=0 \\
\frac{\partial E}{\partial \lambda}=\frac{4 V_{1} V_{2} n}{\pi^{2} \omega L} \cos ^{2}\left(\frac{\alpha}{2}\right) \sin (\beta)-P_{0}=0
\end{array}\right.
$$


From (15) and (16), the optimal solution $(\alpha, \beta)$ for DABIBDC under DPS control can be obtained by the results of the nonlinear equations in (16), and the DPS-based optimized strategy for DAB-IBDC is presented in Fig. 6 . For the proposed strategy, the outer angle $\beta$ is obtained from the output voltage control loop. An optimized calculation model is used to obtain the inner angle $\alpha$ for reducing the current stress/power loss and improving the efficiency of DAB-IBDC.

From (16), the common solution and Pareto front of optimization for inner angle $\alpha$ is further obtained:

$$
\alpha=\arccos \sqrt{\frac{P_{0} \pi^{2} \omega L}{n V_{1} V_{2} \sin (\beta)}}
$$

From (17), since the fluctuations in switching frequency and inductance value are very small compared with the magnitude of normalized transmission power and DC voltages, their influence on optimization result will be very small. Therefore, the optimal inner phase-shift angle $\alpha$ is mainly determined by outer phase-shift angle $\beta$, relatively fixed parameters normalized transmission power $P_{0^{\prime}}$ the HFL voltage ratio $n$, and also DC voltages $V_{1}$ and $V_{2}$.

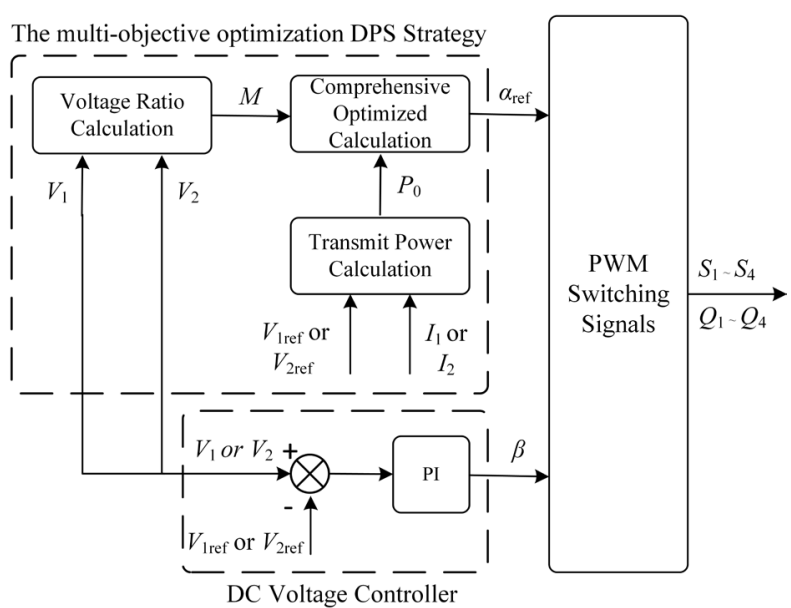

Figure 6: Control framework of proposed multi-objective optimized DPS strategy for DAB-IBDC.

\section{Experiment verification}

To verify the proposed control strategy, a $1 \mathrm{~kW}$ rated DAB-IBDC prototype is established, and the load power rating is rated $1 \mathrm{~kW}$. The detailed parameters are presented in Table 1, and the prototype is shown in Fig. 7.
Table 1: Parameters of DAB-IBDC Prototype.

\begin{tabular}{|l|c|c|}
\hline Parameters & Value & Symbol \\
\hline Primary Side DC Voltage & $50 \mathrm{~V} \sim 150 \mathrm{~V}$ & $\mathrm{~V}_{1}$ \\
\hline Secondary Side DC Voltage & $50 \mathrm{~V} \sim 150 \mathrm{~V}$ & $\mathrm{~V}_{2}$ \\
\hline Switching Frequency & $20 \mathrm{kHz}$ & $\mathrm{f}_{\mathrm{s}}$ \\
\hline Transformer Turn Ratio & $1: 1$ & $\mathrm{n}$ \\
\hline HFL Equivalent Inductor & $30 \mathrm{uH}$ & $\mathrm{L}$ \\
\hline DC-link Capacitance & $150 \mathrm{uF}$ & $\mathrm{C}_{1}, \mathrm{C}_{2}$ \\
\hline Load Resistance & $10 \Omega \sim 100 \Omega$ & $\mathrm{R}$ \\
\hline
\end{tabular}

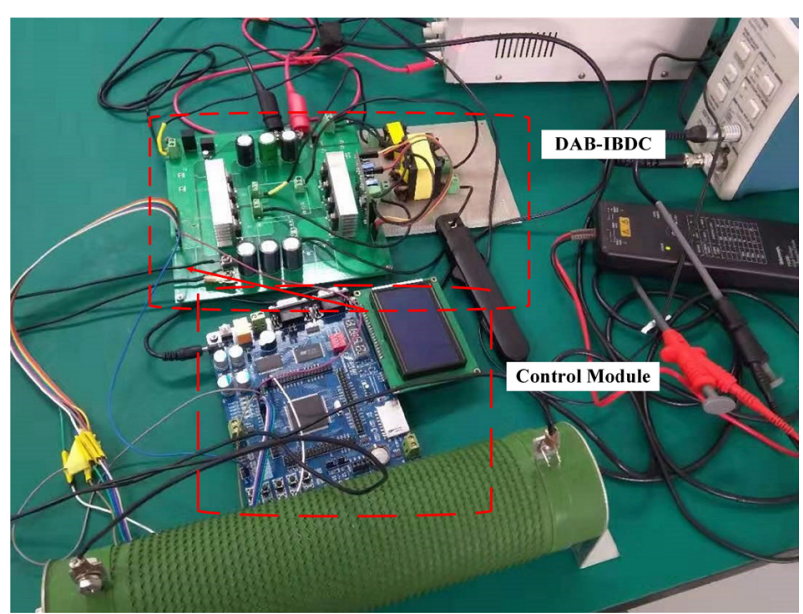

Figure 7: The prototype of DAB-IBDC.

(a)

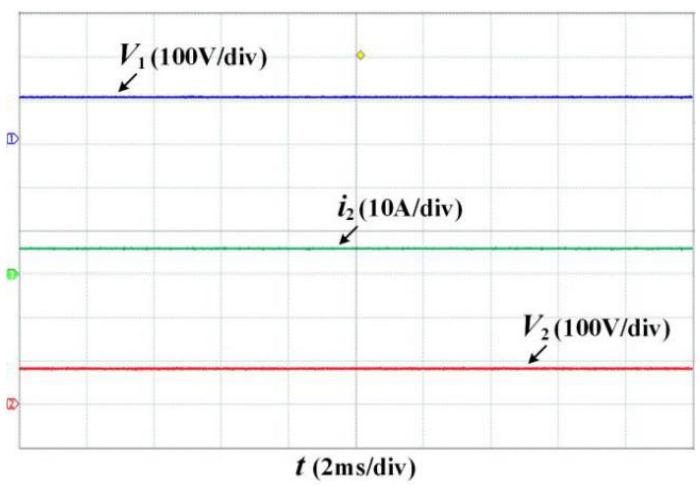

(b)

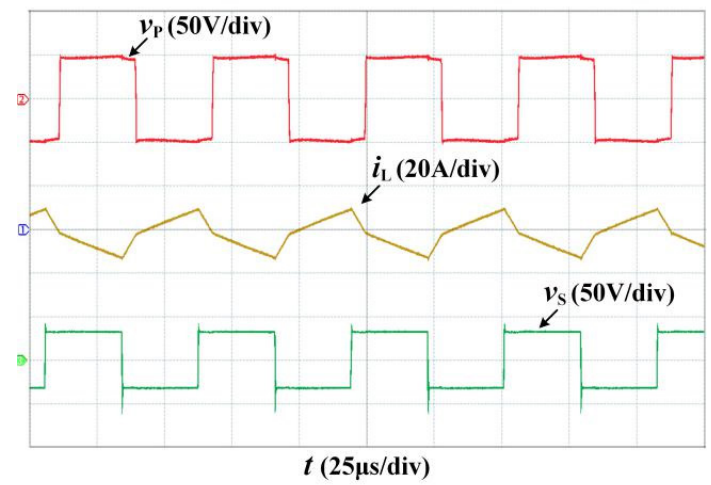

Figure 8: Experiment waveforms under SPS. (a) DC side voltages and current, (b) HFL voltages and current. 
For the DAB-IBDC, Fig. 8 shows the steady-state experiment waveforms under SPS control. It can be seen that,

(a)

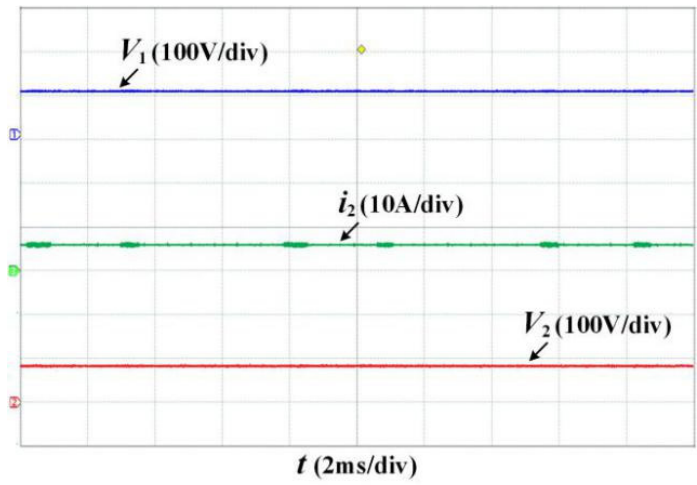

(b)

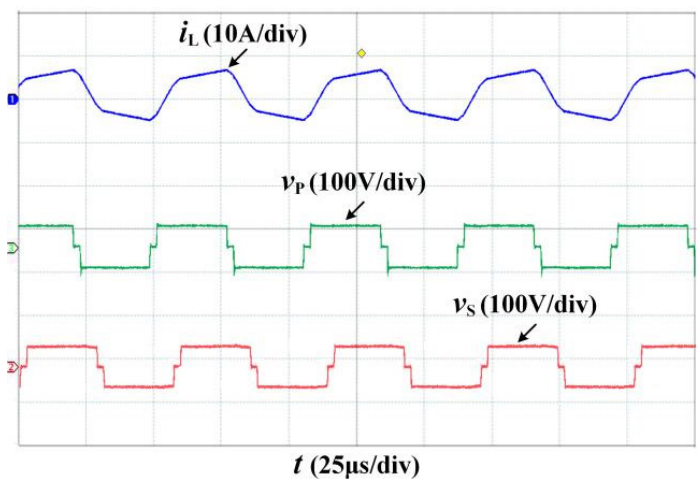

(c)

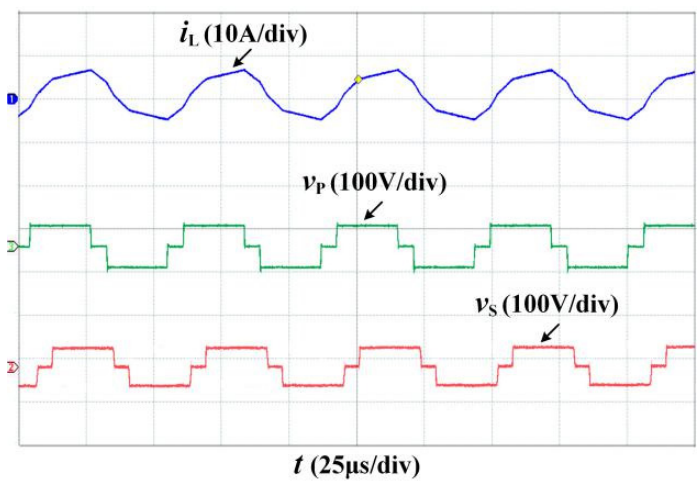

(d)

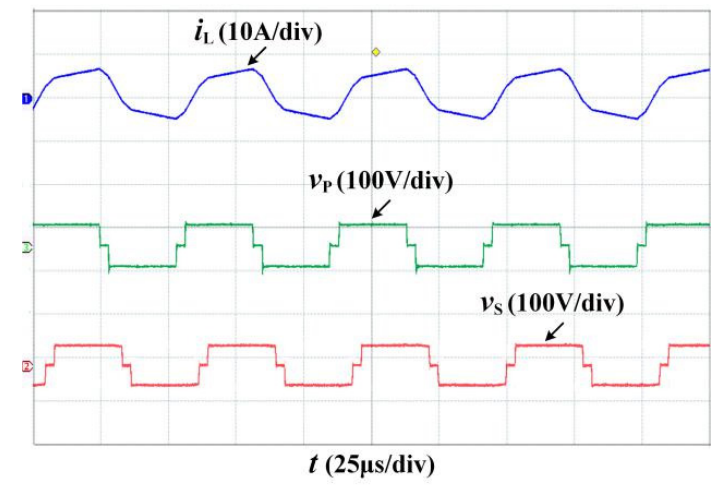

Figure 9: Experiment waveforms under conventional and proposed optimized DPS. (a) DC side Voltages and current of DAB-IBDC, (b) Conventional DPS when $a=$ 0.12 , (c) Conventional DPS when $a=0.25$, (d) Proposed optimized DPS when $a=0.18$. the $V_{1}$ on the primary DC side is $100 \mathrm{~V}$, and the $V_{2}$ on the secondary DC side is regulated at the designed $80 \mathrm{~V}$. The HFL voltages $v_{\mathrm{p}}$ and $v_{\mathrm{s}}$ are both high-frequency square waves, and the frequencies of $v_{p} v_{S}$ and $i_{L}$ are $20 \mathrm{kHz}$. Besides, since the $\mathrm{DC}$ voltages deviate from the conversion ratio 1:1, the HFL current stress and reactive power become high. However, the SPS control could not solve this issue, and the maximum value of HFL current is 10.1 A.

With the same transmission power, Fig. 9(a) and Fig. 9(b) show the experiment waveforms of DAB-IBDC under the conventional DPS control. It can be seen that the DAB-IBDC operates normally, i.e., $V_{1}$ is $100 \mathrm{~V}$ and $V_{2}$ is also regulated at the designed $80 \mathrm{~V}$. Besides, the HFL current stress and reactive power under DPS control are lower than that under SPS control. Thus, the DPS strategy is able to improve the performance of the DAB$\mathrm{IBDC}$ by reducing the maximum value of $\mathrm{HFL}$ current to 9.4A. Moreover, steady-state experiment waveforms of HFL current under conventional DPS and proposed optimized control are presented in Fig. 9(c) and Fig. 9(d). It can be seen that the conventional DPS with a larger

inner phase-shift angle can further reduce the HFL current stress and reactive power, and the value of HFL current under the proposed optimized DPS control can reduce to $8.7 \mathrm{~A}$. Accordingly, the HFL current stress and reactive power under proposed optimized DPS control

(a)

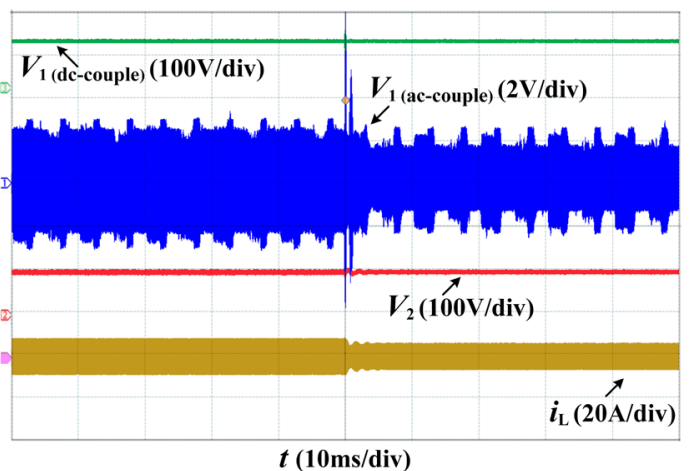

(b)

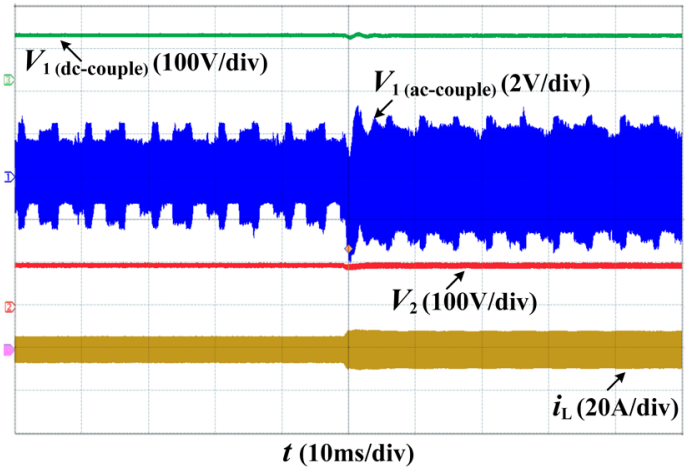

Figure 10: The dynamic-state experiment waveforms of DAB-IBDC under proposed optimized DPS strategy. (a) Load varies from $100 \%$ to $50 \%$; (b) Load varies from $50 \%$ to $100 \%$. 
are lowest compared with that under SPS and conventional DPS.

The dynamic-state waveforms of the DAB-IBDC under the proposed optimized DPS strategy are presented in Fig. 10. According to Fig. 10(a), when the load varies from $100 \%$ to $50 \%$, the voltage ripple of $V_{1}$ decreases,

(a)

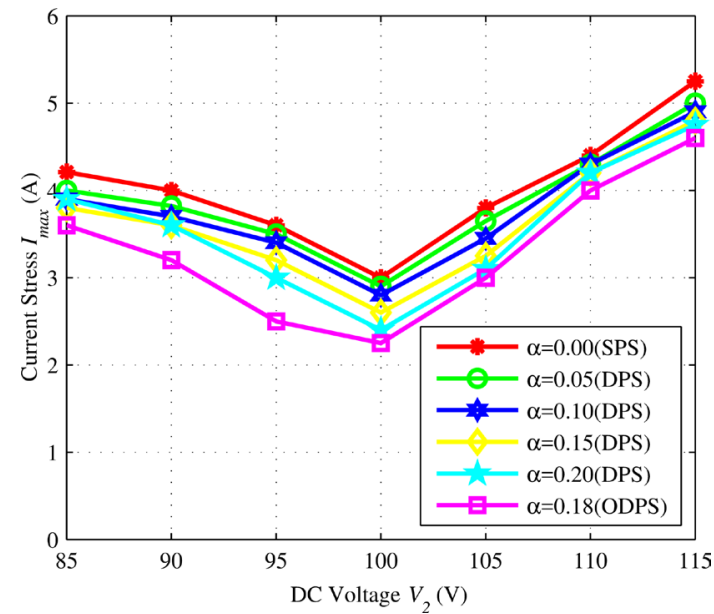

(b)

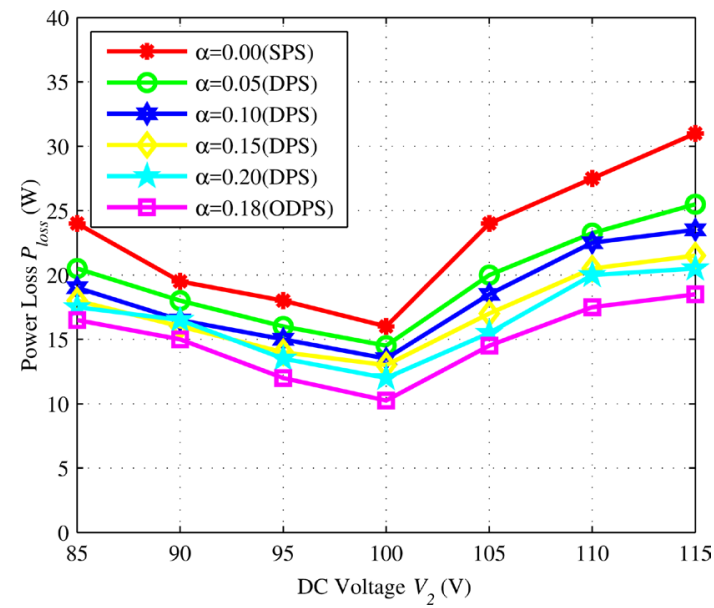

(c)

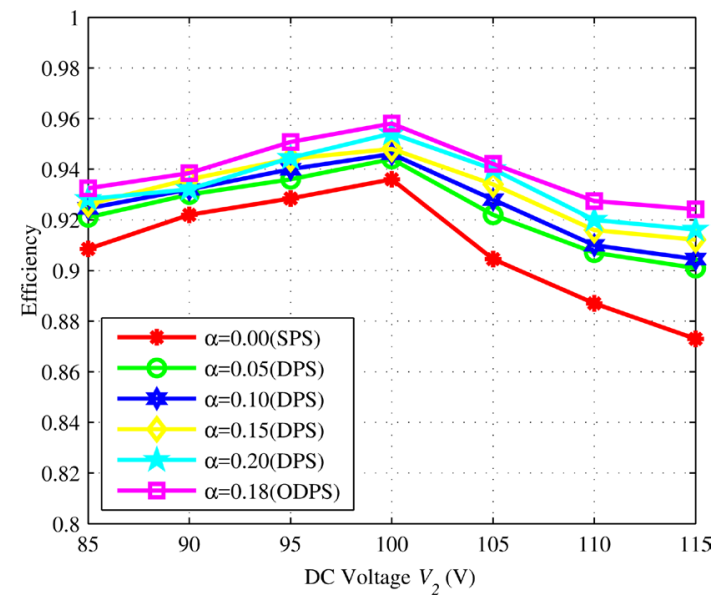

Figure 11: Experimental curves under conventional strategies and proposed optimized DPS (ODPS) strategy. (a) Curves of current stress, (b) Curves of power loss, (c) Curves of efficiency. and $V_{2}$ maintains at $100 \mathrm{~V}$. Besides, the HFL current stress $i_{\mathrm{L}}$ decreases correspondingly. Similarly, when the load varies from $50 \%$ to $100 \%$, the voltage ripple of $V_{1}$ increases, and $V_{2}$ keeps at 100V. In addition, the HFL current stress $i$ increases correspondingly, according to Fig. 10(b). Based on the above analysis, it can be concluded that under the proposed optimized DPS strategy, the $D C$ voltages on both sides of DAB-IBDC maintain at designed value, and the DAB-IBDC operates stably during the dynamic-state.

With the same transmission power and varied $D C$ voltages, Fig. 11(a) shows the current stress of DAB-IBDC under conventional strategies and proposed optimized control strategy. From Fig. 11(a), it can be observed that: under the three control strategies, the lowest current stress occurs when $V 1=V 2=100 \mathrm{~V}$. However, the current stress would become higher because the conversion ratio deviates from 1:1 farther (e.g., V2 drops from $100 \mathrm{~V}$ to $85 \mathrm{~V}$ or increases from $100 \mathrm{~V}$ to $115 \mathrm{~V}$ ). Also, the current stress under DPS control is lower than that under SPS control, and increasing the inner phase-shift angle can further reduce the current stress. In addition, the proposed optimized DPS strategy achieves the lowest current stress for DAB-IBDC among the three strategies.

Similarly, Fig. 11 (b) and Fig. 11(c) present the power loss and efficiency of DAB-IBDC under conventional control strategies and proposed optimized control strategy, respectively. Similar to the results of current stress experiments, under various phase-shift control strategies, the lowest power loss can be achieved when $V 1=V 2=$ $100 \mathrm{~V}$. Once $\mathrm{V} 2$ varies and deviates from the conversion ratio 1:1, it would result in larger power loss and lower efficiency. Meanwhile, lower power loss is achieved by the DPS strategy compared with that under the SPS strategy. Increasing the inner phase-shift angle $\alpha$ can further reduce power loss. In addition, the proposed optimized strategy realizes the lowest power loss, so as to obtain the highest efficiency for DAB-IBDC. Thus, the proposed multi-objective optimized strategy improves the efficiency of DAB-IBDC.

\section{Conclusions}

The DAB-IBDC plays a crucial role in DC distribution networks for realizing galvanic isolation, voltage conversion, power transfer, and bus connection. In this paper, the effect of phase-shift control on power transmission characteristic, current stress, and efficiency of DAB-IB$D C$ is analyzed in detail. Then, to optimize these three features simultaneously, a DPS-based multi-objective optimized control strategy is proposed. The experi- 
ment results obtained from a built DAB-IBDC prototype verify that 1) the DPS control realizes less HFL reactive power, lower current stress, and higher efficiency for DAB-IBDC compared with SPS control, 2) the proposed optimized DPS control strategy optimizes the three features of DAB-IBDC simultaneously. Accordingly, the proposed control strategy can effectively improve the performance of DAB-IBDC, which makes it more adaptable and practical in DC power conversion networks.

\section{Acknowledgments}

This study was funded by the National Natural Science Foundation of China (No.51967012); Scientific Research and Innovation Team Project of Gansu Education Department (2018C-09); and State Grid Gansu Electric Power Company Project (SGGSKY00FJJS1800142).

\section{Conflict of interest}

The authors declare no conflict of interest. The founding sponsors had no role in the design of the study; in the collection, analyses, or interpretation of data; in the writing of the manuscript, and in the decision to publish the results.

\section{References}

1. T. Dragicevic, X. Lu, J. C. Vasquez, and J. M. Guerrero, "DC microgrids - part I: A review of control strategies and stabilization techniques," IEEE Trans. Power Electron., vol. 31, no. 7, pp. 4876-4891, Jul. 2016.

https://doi.org/10.1109/TPEL.2015.2478859

2. D. Liu, Y. Wang, F. Deng, and Z. Chen, "Balanced power device currents based modulation strategy for full-bridge three-level DC/DC converter," IEEE Trans. Power Electron., vol. 35, no. 2, pp. 20082022, Feb. 2020.

https://doi.org/10.1109/TPEL.2019.2918271

3. M. Mojibi and M. Radmehr, "Reliability evaluation of buck converter based on thermal analysis," Inf. MIDEM, vol. 48, no. 4, pp. 217-227, 2018. https://doi.org/10.33180/InfMIDEM2018.404

4. S. Ramasamy, I. R. Chandran, and C. Nallaperumal, "A High Voltage Gain Multiport Zeta-Zeta Converter for Renewable Energy Systems," Inf. MIDEM, vol. 50, no. 3, pp. 215-230, 2020.

https://doi.org/10.33180/InfMIDEM2020.306

5. N. H. van der Blij, L. M. Ramirez-Elizondo, M. T. J. Spaan, and P. Bauer, "A state-space approach to modelling DC distribution systems," IEEE Trans. Power Syst., vol. 33, no. 1, pp. 943-950, Jan. 2018. https://doi.org/10.1109/TPWRS.2017.2691547

6. Y. Wang, Q. Song, Q. Sun, B. Zhao, J. Li, and W. Liu, "Multilevel MVDC link strategy of high-frequencylink DC transformer based on switched capacitor for MVDC power distribution," IEEE Trans. Ind. Electron., vol. 64, no. 4, pp. 2829-2835, Apr. 2017. https://doi.org/10.1109/TIE.2016.2643622

7. B. Zhao, Q. Song, W. Liu, and Y. Sun, "Overview of dual-active-bridge isolated bidirectional DC-DC converter for high-frequency-link power-conversion system," IEEE Trans. Power Electron., vol. 29, no. 8, pp. 4091-4106, Aug. 2014. https://doi.org/10.1109/TPEL.2013.2289913

8. S. P. Engel, M. Stieneker, N. Soltau, S. Rabiee, H. Stagge, and R. W. D. Doncker, "Comparison of the modular multilevel DC converter and the dualactive bridge converter for power conversion in HVDC and MVDC grids," IEEE Trans. Power Electron., vol. 30, no. 1, pp. 124-137, Jan. 2015. https://doi.org/10.1109/TPEL.2014.2310656

9. X. She, A. Q. Huang, and R. Burgos, "Review of solid-state transformer technologies and their application in power distribution systems," IEEE J. Emerg. Sel. Top. Power Electron., vol. 1, no. 3, pp. 186-198, Sep. 2013. https://doi.org/10.1109/JESTPE.2013.2277917

10. Y. Wang, Q. Song, B. Zhao, J. Li, Q. Sun, and W. Liu, "Analysis and optimisation of modulation strategy based on dual-phase-shift for modular multilevel high-frequency-link DC transformer in medium-voltage DC distribution network," IET Power Electron., vol. 11, no. 2, pp. 253-261, 2018. https://doi.org/10.1049/iet-pel.2016.0857

11. X. Xiang, X. Zhang, T. Luth, M. M. C. Merlin, and T. C. Green, "A compact modular multilevel DC-DC converter for high step-ratio MV and HV use," IEEE Trans. Ind. Electron., vol. 65, no. 9, pp. 7060-7071, Sep. 2018.

https://doi.org/10.1109/TIE.2018.2793249

12. K. Zhang, Z. Shan, and J. Jatskevich, "Large- and small-signal average-value modeling of dual-active-bridge DC-DC converter considering power losses," IEEE Trans. Power Electron., vol. 32, no. 3, pp. 1964-1974, Mar. 2017. https://doi.org/10.1109/TPEL.2016.2555929

13. Y. Wang et al., "A multiple modular isolated DC/DC converter with bidirectional fault handling and efficient energy conversion for DC distribution network," IEEE Trans. Power Electron., vol. 35, no. 11, pp. 11502-11517, Nov. 2020. https://doi.org/10.1109/TPEL.2020.2985232

14. S. Chowdhury, P. W. Wheeler, C. Gerada, and C. Patel, "Model predictive control for a dual-active bridge inverter with a floating bridge," IEEE Trans. 
Ind. Electron., vol. 63, no. 9, pp. 5558-5568, Sep. 2016. https://doi.org/10.1109/TIE.2016.2564949

15. J. Riedel, D. G. Holmes, B. P. McGrath, and C. Teixeira, "ZVS soft switching boundaries for dual active bridge DC-DC converters using frequency domain analysis," IEEE Trans. Power Electron., vol. 32, no. 4, pp. 3166-3179, Apr. 2017. https://doi.org/10.1109/TPEL.2016.2573856

16. J. D. Páez, D. Frey, J. Maneiro, S. Bacha, and P. Dworakowski, "Overview of DC-DC converters dedicated to HVDC grids," IEEE Trans. Power Deliv., vol. 34, no. 1, pp. 119-128, Feb. 2019. https://doi.org/10.1109/TPWRD.2018.2846408

17. X. Li and Y. Li, "An optimized phase-shift modulation for fast transient response in a dual-activebridge converter," IEEE Trans. Power Electron., vol. 29, no. 6, pp. 2661-2665, Jun. 2014. https://doi.org/10.1109/TPEL.2013.2294714

18. B. Zhao, Q. Song, W. Liu, and Y. Zhao, "Transient DC bias and current impact effects of high-frequency-isolated bidirectional DC-DC converter in practice," IEEE Trans. Power Electron., vol. 31, no. 4, pp. 3203-3216, Apr. 2016. https://doi.org/10.1109/TPEL.2015.2445831

19. N. Hou, W. Song, and M. Wu, "Minimum-currentstress scheme of dual active bridge DC-DC converter with unified phase-shift control," IEEE Trans. Power Electron., vol. 31, no. 12, pp. 8552-8561, Dec. 2016. https://doi.org/10.1109/TPEL.2016.2521410

20. B. Zhao, Q. Song, W. Liu, and W. Sun, "Currentstress-optimized switching strategy of isolated bidirectional DC-DC converter with dual-phaseshift control," IEEE Trans. Ind. Electron., vol. 60, no. 10, pp. 4458-4467, Oct. 2013. https://doi.org/10.1109/TIE.2012.2210374

21. G. Oggier, G. O. García, and A. R. Oliva, "Modulation strategy to operate the dual active bridge DC-DC converter under soft switching in the whole operating range," IEEE Trans. Power Electron., vol. 26, no. 4, pp. 1228-1236, Apr. 2011. https://doi.org/10.1109/TPEL.2010.2072966

22. A. Rodríguez, A. Vázquez, D. G. Lamar, M. M. Hernando, and J. Sebastián, "Different purpose design strategies and techniques to improve the performance of a dual active bridge with phaseshift control," IEEE Trans. Power Electron., vol. 30, no. 2, pp. 790-804, Feb. 2015. https://doi.org/10.1109/TPEL.2014.2309853

23. F. Krismer and J. W. Kolar, "Efficiency-optimized high-current dual active bridge converter for automotive applications," IEEE Trans. Ind. Electron., vol. 59, no. 7, pp. 2745-2760, Jul. 2012. https://doi.org/10.1109/TIE.2011.2112312
24. B. Zhao, Q. Song, and W. Liu, "Efficiency characterization and optimization of isolated bidirectional DC-DC converter based on dual-phase-shift control for DC distribution application," IEEE Trans. Power Electron., vol. 28, no. 4, pp. 1711-1727, Apr. 2013.

https://doi.org/10.1109/TPEL.2012.2210563

25. H. Bai, Z. Nie, and C. C. Mi, "Experimental comparison of traditional phase-shift, dual-phase-shift, and model-based control of isolated bidirectional DC-DC converters," IEEE Trans. Power Electron., vol. 25, no. 6, pp. 1444-1449, Jun. 2010. https://doi.org/10.1109/TPEL.2009.2039648

26. A. K. Jain and R. Ayyanar, "PWM control of dual active bridge: Comprehensive analysis and experimental verification," IEEE Trans. Power Electron., vol. 26, no. 4, pp. 1215-1227, Apr. 2011. https://doi.org/10.1109/TPEL.2010.2070519

27. S. S. Muthuraj, V. K. Kanakesh, P. Das, and S. K. Panda, "Triple phase shift control of an LLL tank based bidirectional dual active bridge converter," IEEE Trans. Power Electron., vol. 32, no. 10, pp. 8035-8053, Oct. 2017.

https://doi.org/10.1109/TPEL.2016.2637506

28. A. Taylor, G. Liu, H. Bai, A. Brown, P. M. Johnson, and M. McAmmond, "Multiple-phase-shift control for a dual active bridge to secure zero-voltage switching and enhance light-load performance," IEEE Trans. Power Electron., vol. 33, no. 6, pp. 45844588, Jun. 2018.

https://doi.org/10.1109/TPEL.2017.2769638

29. Y. Wang, Q. Song, B. Zhao, J. Li, Q. Sun, and W. Liu, "Quasi-square-wave modulation of modular multilevel high-frequency DC converter for mediumvoltage DC distribution application," IEEE Trans. Power Electron., vol. 33, no. 9, pp. 7480-7495, Sep. 2018.

https://doi.org/10.1109/TPEL.2017.2772833

30. I. A. Gowaid, G. P. Adam, S. Ahmed, D. Holliday, and B. W. Williams, "Analysis and design of a modular multilevel converter with trapezoidal modulation for medium and high voltage DC-DC transformers," IEEE Trans. Power Electron., vol. 30, no. 10, pp. 5439-5457, Oct. 2015. https://doi.org/10.1109/TPEL.2014.2377719

31. Y. Yan, H. Bai, A. Foote, and W. Wang, "Securing full-power-range zero-voltage switching in both steady-state and transient operations for a dualactive-bridge-based bidirectional electric vehicle charger," IEEE Trans. Power Electron., vol. 35, no. 7, pp. 7506-7519, Jul. 2020.

https://doi.org/10.1109/TPEL.2019.2955896

32. Q. Gu, L. Yuan, J. Nie, J. Sun and Z. Zhao, "Current stress minimization of dual-active-bridge DC-DC converter within the whole operating range," IEEE 
J. Emerg. Sel. Top. Power Electron., vol. 7, no. 1, pp. 129-142, Mar. 2019.

https://doi.org/10.1109/JESTPE.2018.2886459

33. O. M. Hebala, A. A. Aboushady, K. H. Ahmed and I. Abdelsalam, "Generic closed-loop controller for power regulation in dual active bridge DC-DC converter with current stress minimization," IEEE Trans. Ind. Electron., vol. 66, no. 6, pp. 4468-4478, Jun. 2019.

https://doi.org/10.1109/TIE.2018.2860535

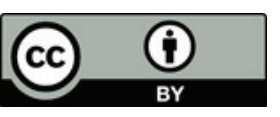

Copyright $@ 2021$ by the Authors. This is an open access article distributed under the Creative Commons Attribution (CC BY) License (https://creativecommons.org/licenses/by/4.0/), which permits unrestricted use, distribution, and reproduction in any medium, provided the original work is properly cited.

Arrived: 31. 01. 2021

Accepted: 23. 08. 2021 